\title{
Characteristics and outcomes of Stanford type A aortic dissection patients with severe post-operation hyperbilirubinemia: a retrospective cohort study
}

Xiaolan Chen ${ }^{1 \dagger}$, Ming Bai ${ }^{1 *+}$, Lijuan Zhao ${ }^{1 \dagger}$, Yangping $\mathrm{Li}^{1}$, Yan Yu${ }^{1}$, Wei Zhang ${ }^{1}$, Feng Ma ${ }^{1}$, Shiren Sun ${ }^{1 *}$ and Xiangmei Chen ${ }^{1,2^{*}}$

\begin{abstract}
Background: Hyperbilirubinemia is one of the common complications after cardiac surgery and is associated with increased mortality. However, to the best of our knowledge, the reports on clinical significance of postoperative severe hyperbilirubinemia in Stanford type A aortic dissection (AAD) patients were limited.

Methods: Patients who underwent surgical treatment for AAD in our center between January 2015 and December 2018 were retrospectively screened. In-hospital mortality, long-term mortality, acute kidney injury (AKI), and the requirement of continuous renal replacement therapy (CRRT) were assessed as endpoints. Univariate and multivariate regression models were employed to identify the risk factors of these endpoints.

Results: After screening, 271 patients were included in our present study. Of the included patients, 222 (81.9\%) experienced postoperative AKI, and 50 (18.5\%) received CRRT. The in-hospital mortality was 30.3\%. The 1-year, 2-year, and 3-year cumulative mortality were 32.9, 33.9, and 35.3\%, respectively. Multivariate Logistic regression analysis indicated that age $(P<0.033)$, AKI stage $3(P<0.001)$, the amount of blood transfusion after surgery $(P=0.019)$, mean arterial pressure (MAP) in the first postoperative day $(P=0.012)$, the use of extracorporeal membrane oxygenation (ECMO) $(P=0.02)$, and the peak total bilirubin $(\mathrm{TB})$ concentration $(P=0.023)$ were independent risk factors of in-hospital mortality. The optimal cut-off value of peak TB on predicting in-hospital mortality was $121.2 \mu \mathrm{mol} / \mathrm{L}$. Patients with postoperation $T B \geq 121 \mu \mathrm{mol} / \mathrm{L}$ was associated with worse long-term survival as well.

Conclusions: Severe post-operation hyperbilirubinemia is a common clinical situation in patients had AAD repair. In AAD patients with severe post-operation hyperbilirubinemia, older age, lower MAP, increased blood transfusion, stage $3 \mathrm{AKI}$, the use of ECMO, and the increased peak TB lead to increase in-hospital mortality.
\end{abstract}

Keywords: Stanford type a aortic dissection, Hyperbilirubinemia, Acute kidney injury, Continuous renal replacement therapy

\footnotetext{
* Correspondence: mingbai1983@126.com; sunshiren@medmail.com.cn; xmchen301@126.com

†Xiaolan Chen, Ming Bai and Lijuan Zhao contributed equally to this work. ${ }^{1}$ The Nephrology Department of Xijing Hospital, the Fourth Military Medical University, No. 127 Changle West Road, Xi'an 710032, Shaanxi, China

Full list of author information is available at the end of the article
}

(c) The Author(s). 2020 Open Access This article is licensed under a Creative Commons Attribution 4.0 International License, which permits use, sharing, adaptation, distribution and reproduction in any medium or format, as long as you give appropriate credit to the original author(s) and the source, provide a link to the Creative Commons licence, and indicate if changes were made. The images or other third party material in this article are included in the article's Creative Commons licence, unless indicated otherwise in a credit line to the material. If material is not included in the article's Creative Commons licence and your intended use is not permitted by statutory regulation or exceeds the permitted use, you will need to obtain permission directly from the copyright holder. To view a copy of this licence, visit http://creativecommons.org/licenses/by/4.0/ The Creative Commons Public Domain Dedication waiver (http://creativecommons.org/publicdomain/zero/1.0/) applies to the data made available in this article, unless otherwise stated in a credit line to the data. 


\section{Introduction}

Aortic dissection (AD) is an acute life-threatening condition with a prevalence of about $3 / 100,000$ per year. The International Registry of $\mathrm{AD}$ revealed that $67 \%$ of $\mathrm{AD}$ patients presented with Stanford type A aortic dissection (AAD), which was characterized as the involvement of the ascending aorta. And, approximately $86 \%$ of AAD patients required swift open cardiac surgery to avoid fatal complications such as aortic rupture and cardiac tamponade [1$3]$. In spite of the improvement in medical management and surgical technique, the averaged in-hospital mortality of AAD was as high as $14 \%$ [4].

Hyperbilirubinemia is a common severe complication after cardiac operation [5]. The reported incidence of post-operation hyperbilirubinemia varied widely (10 to $57 \%)$ and related to the severity of cardiac diseases and the type of cardiac surgery [5-8]. Additionally, hyperbilirubinemia was reported increased major adverse events and in-hospital and 30-day mortality for patients with cardiac surgery including aortic dissection surgery $[9,10]$. Nevertheless, the effects of hyperbilirubinemia on patient prognosis with different types of surgery were heterogeneous $[6,7,11-13]$. For patients undergoing cardiac surgery with cardiopulmonary bypass $(\mathrm{CPB})$, recent study suggested that severe hyperbilirubinemia (5 times the normal upper limit) instead of mild bilirubin significantly increased patient mortality and a maximum bilirubin of $25.5 \mathrm{mg} / \mathrm{dl}$ was associated with $99 \%$ mortality [14]. Mild or moderate hyperbilirubinemia might be associated with hemolysis, cardiotomy suction, gaseous micro-emboli, and blood transfusions during $\mathrm{CPB}$, which were temporary and revisable. However, severe hyperbilirubinemia could induce oxidative stress and cell apoptosis, which cause respiratory failure, thrombocytopenia, and even neurological dysfunction, and consequently promote multiple organ dysfunction syndrome (MODS) and increase patient inhospital mortality. However, the mortality of patients with severe post-operation hyperbilirubinemia remained significant divergence. Some of these patients recovered within weeks, others progressed to MODS and resulted in short-term death. The description of the characteristics, outcome, and risk factors of in-hospital and long-term mortality could help clinicians on the understanding patients with severe post-operation hyperbilirubinemia and the estimation of the patient prognosis, which was important for patient consulting and decision making. Additionally, the pathogenesis, disease severity classification, prognosis, and operation method are different between different cardiac diseases. The inclusion of all kinds of cardiac surgery in one study most likely would reduce the specificity and repeatability of the conclusions. Up to now, the reports on the characteristics and outcomes of AAD surgery patients with severe post-operation hyperbilirubinemia are limited.
Therefore, the purpose of our present study is to describe the clinical characteristics and to investigate the risk factors of mortality for AAD surgery patients who had severe post-operation hyperbilirubinemia.

\section{Patients and method}

\section{Study design and patients selection}

Our present study was retrospectively designed. Consecutive patients who underwent surgery for AD in our center between January 2015 and December 2018 were screened. $\mathrm{AD}$ was proven by enhanced computed tomography and defined as type A or type B according to the Stanford classification. Postoperative severe hyperbilirubinemia was defined as the occurrence of serum TB concentration $\geq$ $85.5 \mu \mathrm{mol} / \mathrm{l}$ (5 times the normal upper limit) in any measurement during the hospital staying after AAD surgery. Patients were excluded if they had any of the following conditions: (1) serum TB concentration < $85.5 \mu \mathrm{mol} / \mathrm{l}$, (2) age < 18 years; (3) Stanford type B aortic dissection; (4) the occurrence of severe hyperbilirubinemia before surgery; (5) severe hyperbilirubinemia caused by the reoperation during hospitalization. The ethics committee of the Xijing hospital approved this retrospective study and waived the requirement of informed consent for the use of patients' medical data.

\section{Surgical procedure}

The use of surgical techniques has developed during the study period. However, the basic principles for repair of AAD have no change, including (1) prompt establishment of $\mathrm{CPB},(2)$ resection of the primary entry site by open distal anastomosis under deep hypothermic circulatory arrest and selective anterograde cerebral perfusion, (3) preservation of the aortic valve whenever possible, and (4) aortic arch replacement in patients with an entry site located in or extending into the aortic arch. Aortic root replacement with a composite prosthesis and reimplantation of the coronary arteries by the modified Bentall technique was performed in patients with conspicuous dilatation of the aortic root.

\section{Data collection}

Demographic data, comorbidities, and operation details were retrieved from our hospital's electronic medical record system. All the routine laboratory data was recorded before operation (the nearest to the time of surgery) and in the post-operation period. The severity of illness before and after surgery was assessed by using the acute physiology and chronic health evaluation II (APACHE II), sequential organ failure assessment (SOFA) score, and model for end-stage liver disease (MELD) score. Urine output was recorded every day after the surgery. 


\section{Outcomes and definition}

Post-operation outcomes including the amount of blood transfusion, mechanical ventilation time, the use of extracorporeal membrane oxygenation (ECMO), intraaortic balloon pump (IABP), AKI, the usage of CRRT, bilirubin adsorption (BA) or plasma exchange (PE), and vasoactive agent, the duration of hospitalization, ICU stay time, and in-hospital mortality. For those patients who were alive on discharge, telephone survey was performed to obtain the patients long-term outcome.

Kidney Disease Improving Global Outcomes (KDIGO) criteria [15] based on SCr or urine output was employed to diagnose and grade AKI. The latest $\mathrm{SCr}$ concentration before surgery was defined as preoperative $\mathrm{SCr}$ concentration. The decision to start CRRT was made at the discretion of the attending nephrologist. Main indications for starting CRRT were progressive AKI, fluid overload, hyperkalemia, and severe metabolic acidosis.

\section{Statistical analysis}

Continuous variables are presented as mean \pm standard deviation. Categorical variables are presented as frequencies with percentages. To evaluate the differences between groups, the independent sample $t$-test was used for continuous variables, whereas the chi-square test or Fisher's exact test was used for categorical variables. Factors significantly associated with these endpoints in univariate analysis were included in the multivariate logistic regression analysis or Cox proportional hazard analysis to identify the independent risk factors. Accumulated survival proportion was estimated with the KaplanMeier method, and the between-group differences of survival proportion were assessed using the log-rank test. Area under the receiver operating characteristic curve (AUC-ROC) was calculated to assess peak TB concentration on the ability to detect in-hospital mortality. Youden index was used for assessment of optimal cut-off values. For all analyses, all statistical tests were 2sided, and a $P$-value $<0.05$ was considered as statistically significant. Data were analyzed using SPSS version 22.0 software (SPSS, Inc., Chicago, IL, USA).

\section{Result}

\section{Patient characteristics}

Of the 2210 screened patients, 279 patients (12.6\%) developed severe post-operation hyperbilirubinemia. Of these patients, 2, 3, and 3 were excluded because of Stanford type B aortic dissection, preoperative $\mathrm{TB} \geq$ $85.5 \mu \mathrm{mol} / \mathrm{l}$, and severe post-operation hyperbilirubinemia caused by reoperation during this hospitalization, respectively. Ultimately, $271 \mathrm{AAD}$ surgery patients with severe post-operation hyperbilirubinemia were included in our present study (Fig. 1).

The baseline characteristics of the included patients were summarized in Table 1 . There were 223 male and 48 female, and the mean age of the patients was $49.1 \pm$ 11.0 years. AAD surgery involved the ascending aortic in $83.8 \%$ patients, aortic valve in $70.7 \%$ patients, aortic arch in $86 \%$ patients, and coronary artery in $17 \%$ patients. Preoperative TB concentration was $25.0 \pm 15.0 \mu \mathrm{mol} / \mathrm{l}$.

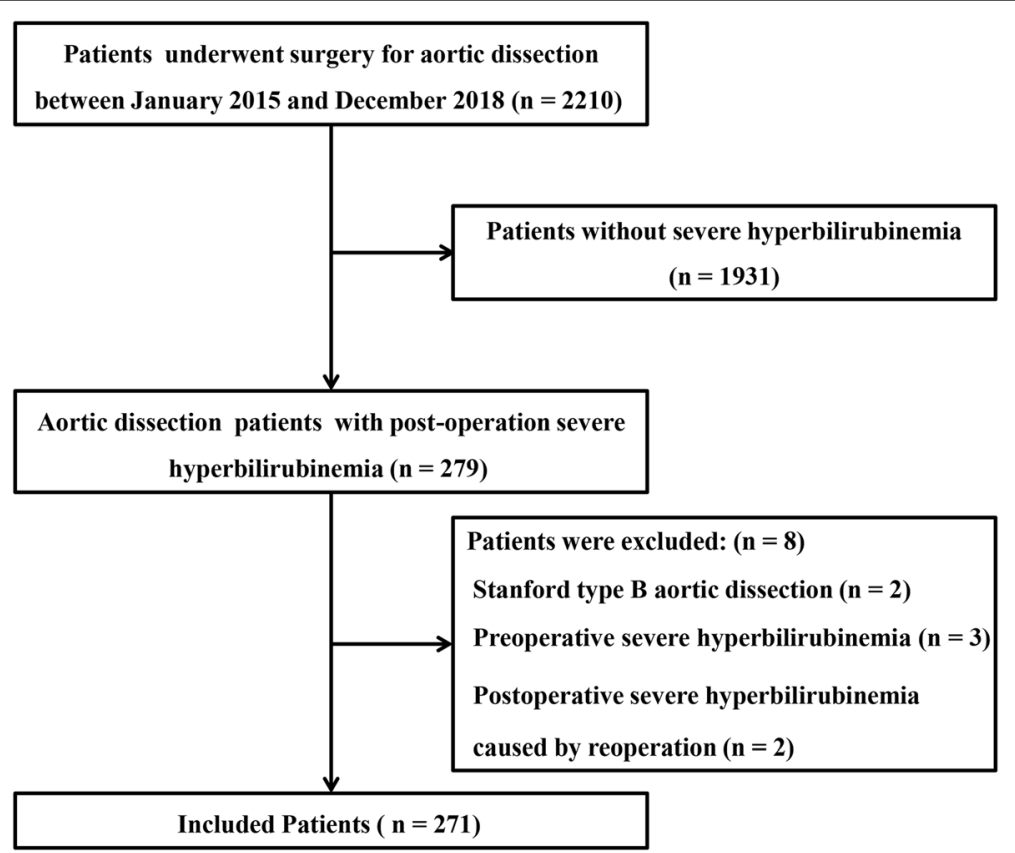

Fig. 1 Patient inclusion flow chart 
Table 1 Baseline characteristics of the included patients

\begin{tabular}{|c|c|}
\hline Variables & Value \\
\hline \multicolumn{2}{|l|}{ Preoperative } \\
\hline Age, mean \pm SD (years) & $49.1 \pm 11.0$ \\
\hline Male, n (\%) & $223(82.3 \%)$ \\
\hline \multicolumn{2}{|l|}{ Co-morbidity } \\
\hline Hypertension, n (\%) & $158(58.3 \%)$ \\
\hline Diabetes, n (\%) & $3(1.1 \%)$ \\
\hline Cerebrovascular disease, n (\%) & $16(5.9 \%)$ \\
\hline Previous cardiac surgery, n (\%) & $8(2.9 \%)$ \\
\hline APACHEll score, mean \pm SD & $9.2 \pm 3.2$ \\
\hline MELD score, mean \pm SD & $9.2 \pm 4.1$ \\
\hline SOFA score, mean \pm SD & $2.1 \pm 1.5$ \\
\hline MAP, mean $\pm S D(m m / H g)$ & $90.5 \pm 12.9(70-105)$ \\
\hline $\mathrm{TB}$, mean $\pm \mathrm{SD}(\mu \mathrm{mol} / \mathrm{l})$ & $\uparrow 25.0 \pm 15.0(3.4-20.5)$ \\
\hline $\mathrm{CB}$, mean $\pm \mathrm{SD}(\mu \mathrm{mol} / \mathrm{l})$ & $\uparrow 7.8 \pm 8.1(0.0-6.8)$ \\
\hline $\mathrm{WBC}$, mean $\pm \mathrm{SD}\left(10^{9} / \mathrm{l}\right)$ & $\uparrow 11.7 \pm 5.0(3.5-9.5)$ \\
\hline $\mathrm{Hb}$, mean $\pm \mathrm{SD}(\mathrm{g} / \mathrm{l})$ & $136.1 \pm 19.9(130-175)$ \\
\hline $\mathrm{PLT}$, mean $\pm \mathrm{SD}\left(10^{9} / \mathrm{l}\right)$ & $\uparrow 157.2 \pm 68.5(125-350)$ \\
\hline $\mathrm{SCr}$, mean $\pm \mathrm{SD}(\mu \mathrm{mol} / \mathrm{l})$ & $\uparrow 111.1 \pm 38.3(57-111)$ \\
\hline $\mathrm{PT}$, mean $\pm \mathrm{SD}(\mathrm{s})$ & $12.0 \pm 2.2(9.8-12.1)$ \\
\hline \multicolumn{2}{|l|}{ Intraoperative } \\
\hline \multicolumn{2}{|l|}{ Type of operation } \\
\hline Ascending aorta, $\mathrm{n}(\%)$ & $227(83.8 \%)$ \\
\hline Aortic valve & $191(70.7 \%)$ \\
\hline Aortic arch, n (\%) & $233(86 \%)$ \\
\hline Coronary artery, n (\%) & $46(17 \%)$ \\
\hline Operation duration, mean \pm SD (h) & $6.8 \pm 1.6$ \\
\hline $\mathrm{CPB}$ time, mean $\pm \mathrm{SD}(\mathrm{min})$ & $226.5 \pm 60.9$ \\
\hline ACC time, mean $\pm S D(\min )$ & $102.2 \pm 28.0$ \\
\hline Arrest time, mean $\pm \mathrm{SD}$ (min) & $25.1 \pm 14.4$ \\
\hline The amount of blood transfusion $(U)$ & $18.8 \pm 10.6$ \\
\hline \multicolumn{2}{|l|}{ Postoperative } \\
\hline APACHE II score & $16.9 \pm 2.5$ \\
\hline SOFA score & $12.1 \pm 2.6$ \\
\hline Meld score & $18.6 \pm 4.4$ \\
\hline$A S T$, mean $\pm S D(U / L)$ & $\uparrow 347.6 \pm 1387.2(9-50)$ \\
\hline $\mathrm{ALT}$, mean $\pm \mathrm{SD}(\mathrm{U} / \mathrm{L})$ & $\uparrow 164.4 \pm 526.6(9-50)$ \\
\hline $\mathrm{TB}$, mean $\pm \mathrm{SD}(\mu \mathrm{mol} / \mathrm{l})$ & $\uparrow 189.1 \pm 74.6(3.4-20.5)$ \\
\hline$C B$, mean $\pm S D(\mu \mathrm{mol} / \mathrm{l})$ & $\uparrow 110.7 \pm 37.9(0.0-6.8)$ \\
\hline $\mathrm{WBC}$, mean $\pm \mathrm{SD}\left(10^{9} / \mathrm{l}\right)$ & $\uparrow 12.9 \pm 4.8(3.5-9.5)$ \\
\hline $\mathrm{Hb}$, mean $\pm \mathrm{SD}(\mathrm{g} / \mathrm{l})$ & $112.9 \pm 16.6(130-175)$ \\
\hline $\mathrm{PLT}$, mean $\pm \mathrm{SD}\left(10^{9} / \mathrm{l}\right)$ & $\downarrow 99.8 \pm 49.5(125-350)$ \\
\hline $\mathrm{SCr}$, mean $\pm \mathrm{SD}(\mu \mathrm{mol} / \mathrm{l})$ & $\uparrow 162.8 \pm 71.8(57-111)$ \\
\hline $\mathrm{PT}$, mean $\pm \mathrm{SD}(\mathrm{s})$ & $13.6 \pm 2.9(9.8-12.1)$ \\
\hline Peak TB level, mean \pm SD $(\mu \mathrm{mol} / \mathrm{l})$ & $150.9 \pm 93.0$ \\
\hline
\end{tabular}

Table 1 Baseline characteristics of the included patients (Continued)

\begin{tabular}{ll}
\hline Variables & Value \\
\hline Peak TB level > $171 \mu \mathrm{mol} / \mathrm{l}, \mathrm{n}(\%)$ & $55(20.4 \%)$ \\
Peak TB level $>340 \mu \mathrm{mol} / \mathrm{l}, \mathrm{n}(\%)$ & $12(4.4 \%)$ \\
Time to peak TB level, mean \pm SD (d) & $3.8 \pm 3.0$ \\
Time to peak TB level $>5 \mathrm{~d}, \mathrm{n}(\%)$ & $47(17.4 \%)$ \\
\hline
\end{tabular}

ACC Aortic cross clamp, APACHEIl Acute physiology and chronic health evaluation II, $C B$ Conjugated bilirubin, $C P B$ Cardiopulmonary bypass, $H b$ Hemoglobin, MAP Mean arterial pressure, MELD Model for end-stage liver disease, min minute, $P L T$ Platelet, PT Prothrombin time, SCr Serum creatinine, $S D$ Standard deviation, SOFA Sequential organ failure assessment, TB Total bilirubin, WBC White blood cell

Parentheses provide normal ranges for the depicted values; $\uparrow$ indicate variables greater than normal range and $\downarrow$ indicate variables less than normal range

The mean onset time of severe hyperbilirubinemia was $2.8 \pm 1.3$ days after AAD surgery. The mean peak serum TB concentration was $150.9 \pm 93.0 \mu \mathrm{mol} / \mathrm{l}$ and the averaged time to peak TB concentration was $3.8 \pm 3.0$ days after AAD surgery. The change of TB concentration during the 7 days after surgery was showed in Fig. 2. The median follow-up time was 18.63 (0.5-55.9) months. And, 3 patients were lost to follow-up. The time of lost to follow-up was 16-, 95-, and 365-day after the surgery, respectively.

\section{Postoperative AKI}

Of the 271 included patients, 222 patients (82.1\%) had AKI after AAD surgery, of which 102 (40.2\%), 34 $(12.5 \%)$, and $84(29.2 \%)$ were stage 1 , stage 2 , and stage 3 AKI (Table 2), respectively. The results of univariate and multivariate logistic regression are presented in Table 3. In the univariate analysis, age, hypertension, preoperative SCr concentration, APACHE II score, and MELD score, operation time, and CPB time were associated with the occurrence of postoperative AKI. Multivariate analysis indicated that increased age (OR 1.056,

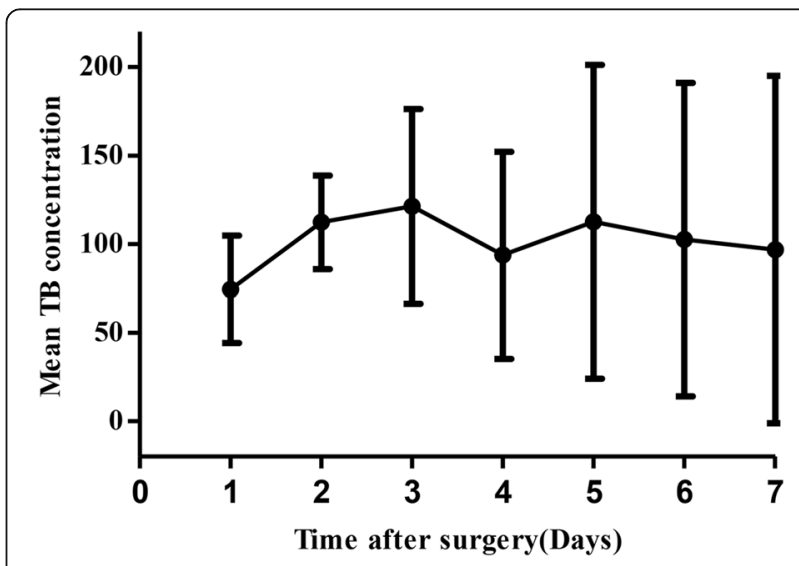

Fig. 2 The averaged serum total bilirubin concentration during the postoperative seven days 
Table 2 The major outcomes of the included patients

\begin{tabular}{|c|c|}
\hline Variables & Value \\
\hline In-hospital mortality, n (\%) & $82(30.3 \%)$ \\
\hline \multicolumn{2}{|l|}{ Cause of death } \\
\hline Multiple organ failure, n (\%) & $40(48.8 \%)$ \\
\hline Heart failure, n (\%) & $35(42.7 \%)$ \\
\hline Hemorrhagic shock, n (\%) & $2(2.4 \%)$ \\
\hline Sepsis, n (\%) & $5(6.1 \%)$ \\
\hline Reoperation, n (\%) & $17(6.3 \%)$ \\
\hline AKI, n (\%) & $222(81.9 \%)$ \\
\hline \multicolumn{2}{|l|}{ Stage of AKI } \\
\hline Stage $1, \mathrm{n}(\%)$ & $102(40.2 \%)$ \\
\hline Stage $2, n(\%)$ & $34(12.5 \%)$ \\
\hline Stage $3, \mathrm{n}(\%)$ & $84(29.2 \%)$ \\
\hline Use of CRRT, n (\%) & $50(18.5 \%)$ \\
\hline Use of PE/BA, n (\%) & $11(14.1 \%)$ \\
\hline Use of IABP, n (\%) & $1(0.4 \%)$ \\
\hline Use of ECMO, n (\%) & $7(2.6 \%)$ \\
\hline Use of vasoactive agent, $\mathrm{n}(\%)$ & $173(63.8 \%)$ \\
\hline Mechanical ventilation time, mean \pm SD (days) & $3.3 \pm 5.7$ \\
\hline The amount of blood transfusion, mean \pm SD $(U)$ & $34.8 \pm 43.3$ \\
\hline In hospital time, mean \pm SD (days) & $19.8 \pm 10.7$ \\
\hline ICU stay time, mean \pm SD (days) & $6.6 \pm 6.3$ \\
\hline Onset of severe hyperbilirubinemia, mean \pm SD (days) & $2.8 \pm 1.3$ \\
\hline
\end{tabular}

$A K I$ Acute kidney injury, BA Bilirubin adsorption, CRRT Continuous renal replacement therapy, ECMO Extracorporeal membrane oxygenation, IABP Intraaortic balloon pump, ICU Intensive care unit, PE Plasma exchange

95\%CI 1.026-1.088, $P<0.001)$, higher preoperative $\mathrm{SCr}$ concentration (OR 1.026, 95\%CI 1.010-1.043, $P=0.002$ ), and prolonged CPB time (OR 1.007, 95\% CI 1.000-1.013, $P=0.042$ ) were identified as independent risk factors of AKI in AAD surgery patients with severe post-operation hyperbilirubinemia.

\section{Postoperative CRRT}

Of the included patients, 50 (18.5\%) patients received CRRT after AAD surgery. Univariate analysis indicated that male, preoperative $\mathrm{SCr}$ concentration, APACHE II score, MELD score, and aortic cross-clamp (ACC) time were associated with the need for CRRT. In the multivariate logistic regression analysis, only preoperative $\mathrm{SCr}$ concentration (OR 1.011, 95\%CI 1.002-1016, $P=0.003$ ) was identified as an independent predictor of the acceptance of CRRT (Table 3).

\section{In-hospital mortality}

There were 82 (30.3\%) in-hospital deaths. The leading causes of death were multiple organ failure $(48.8 \%)$ and heart failure (42.7\%). Other causes included sepsis (6.1\%) and hemorrhagic shock (2.4\%) (Table 2). Univariate analysis revealed that 20 pre-operation, intra-operation, and post-operation factors were associated with inhospital mortality. After the adjustment of the important clinical parameters, independent risk factors of inhospital mortality identified by multivariate logistic analysis included age (OR 1.005, 95\%CI 1.004-1.099, $P=$ 0.033), the amount of blood transfusion (OR 1.018, 95\%CI 1.003-1.033, $P=0.019$ ), stage 3 AKI (OR 46.134, 95\%CI 5.436-391.525, $P<0.001$ ), the use of ECMO (OR 20.795, 95\%CI 1.620-266.917, $P=0.02$ ), and the peak TB concentration (OR 1.017, 95\%CI 1.002-1.032, $P=$ $0.023)$. Postoperative MAP tended to be a protective factor (OR 0.955, 95\%CI 0.922-0.990, $P=0.012$, Table 4, model 1).

ROC analysis (Supplementary figure 1) identified that peak TB concentration was associated with increased mortality, and the optimal cut-off value identified by the Youden index was $121.2 \mu \mathrm{mol} / \mathrm{l}$ (sensitivity: $72 \%$, specificity: 60\%). And, the multivariate analysis revealed that patients with peak TB concentration $\geq 121.2 \mu \mathrm{mol} / \mathrm{l}$ had a significantly higher risk of in-hospital mortality $(\mathrm{OR}=$ 2.681, 95\%CI 1.119-6.425, $P=0.027$, Table 4, model 2), compared with the patients with peak TB concentration $<121.2 \mu \mathrm{mol} / \mathrm{l}$.

\section{Long-term mortality}

Of the 12 patients who died after discharge, 4 had nonAKI, 3 had stage 1 AKI, 3 had stage 2 AKI, and 2 had stage 3 AKI during their hospital stay, respectively. The accumulated 1-year, 2-year, and 3-year mortality proportions were $32.9,33.9$, and $35.3 \%$, respectively (Fig. 3a). The risk factors of long-term mortality were presented in Table 5. Univariate analysis revealed 20 factors, including the post-operation AKI, the acceptance of CRRT and ECMO, and the peak TB concentration $\geq$ $121.2 \mu \mathrm{mol} / \mathrm{l}$ (Fig. 3b-e), were significantly related to patient long-term mortality. Multivariate COX regression analysis revealed that stage 3 AKI (HR 12.604, 95\% CI $5.002-31.762, P<0.001)$ significantly increased longterm mortality, compared with patients without AKI. The use of ECMO (HR 12.167, 95\%CI 4.588-32.264, $P<$ 0.001) was identified as an independent predictor of long-term mortality as well. In contrast, postoperative MAP (HR 0.979, 95\%CI 0.962-0.995, $P=0.012$ ) was identified as an independent protective factor of longterm mortality.

\section{Discussion}

It has been reported that severe hyperbilirubinemia was associated with increased mortality in patients underwent cardiac surgery $[12,14,16]$. Nevertheless, the mortality of patients with severe hyperbilirubinemia remained significant divergence. Up to now, little focus was aimed on the real risk of patients with severe 
Table 3 Logistic regression analysis for postoperative AKI and CRRT

\begin{tabular}{|c|c|c|c|c|}
\hline \multirow[t]{2}{*}{ Characteristic } & \multicolumn{2}{|c|}{ Univariate logistic regression } & \multicolumn{2}{|c|}{ Multivariate logistic regression } \\
\hline & $\mathrm{OR}(95 \% \mathrm{Cl})$ & $\boldsymbol{P}$ value & $\mathrm{OR}(95 \% \mathrm{Cl})$ & $\boldsymbol{P}$ value \\
\hline \multicolumn{5}{|l|}{ Postoperative AKI } \\
\hline Age & $1.061(1.032-1.092)$ & $<0.001$ & $1.056(1.026-1.088)$ & $<0.001$ \\
\hline Hypertension (yes/no) & $2.766(1.469-5.208)$ & 0.002 & & \\
\hline \multicolumn{5}{|l|}{ Preoperative } \\
\hline $\mathrm{SCr}$ & $1.030(1.014-1.047)$ & $<0.001$ & $1.026(1.010-1.043)$ & 0.002 \\
\hline APACHE II score & $1.399(1.213-1.615)$ & $<0.001$ & & \\
\hline MELD score & $1.130(1.035-1.233)$ & 0.007 & & \\
\hline Operation duration & $1.346(1.089-1.633)$ & 0.006 & & \\
\hline CPB time & $1.008(1.001-1.014)$ & 0.015 & $1.007(1.000-1.013)$ & 0.042 \\
\hline \multicolumn{5}{|l|}{ Postoperative CRRT } \\
\hline Male (yes/no) & $4.006(1.192-13.462)$ & 0.025 & & \\
\hline \multicolumn{5}{|l|}{ Preoperative } \\
\hline $\mathrm{SCr}$ & $1.011(1.003-1.018)$ & 0.004 & $1.009(1.002-1016)$ & 0.017 \\
\hline APACHE II score & $1.333(1.033-1.244)$ & 0.008 & & \\
\hline MELD score & $1.083(1.007-1.164)$ & 0.032 & & \\
\hline ACC time & $1.011(1.000-1.022)$ & 0.049 & & \\
\hline
\end{tabular}

ACC Aortic cross clamp, AKI Acute kidney injury, APACHEIl Acute physiology and chronic health evaluation II, CPB Cardiopulmonary bypass, CRRT Continuous renal replacement therapy, MELD Model for end-stage liver disease, $\mathrm{SCr}$ Serum creatinine

hyperbilirubinemia after AAD surgery. Our presented study had several findings. Firstly, the occurrence of AKI, the requirement for CRRT, and the in-hospital mortality were higher than previous studies of patients undergoing AAD surgery without severe hyperbilirubinemia. Secondly, age, preoperative $\mathrm{SCr}$ concentration, and $\mathrm{CPB}$ time were independent risk factors for postoperative AKI, and preoperative SCr concentration was an independent risk factor for post-operation CRRT as well. Finally, the peak TB concentration, post-operation stage $3 \mathrm{AKI}$, the total amount of blood transfusion after AAD surgery, the use of ECMO, and low MAP after surgery were significantly associated with mortality.

\section{AAD patients with severe hyperbilirubinemia were associated with worse prognosis}

The analysis of our present cohort of AAD patients with severe post-operation hyperbilirubinemia showed an overall incidence of post-operation AKI of $81.9 \%$, a requirement for CRRT of $18.5 \%$, and the in-hospital mortality increased from $14 \%$ in all patients to $30.3 \%$ in those with post-operative hyperbilirubinemia. In previous studies of AAD patients underwent surgical treatment without severe post-operation hyperbilirubinemia, the reported AKI incidences were ranged from 40 to $78 \%$ [17-25], the reported incidences of requirement for CRRT were ranged from 3 to $8 \%[21,25]$, and the reported in-hospital mortalities were ranged from 15 to $26 \%[18,21,25-27]$. The discrepancy most likely attributed to the fact that all of the included AAD patients in our study developed severe hyperbilirubinemia. The development of severe hyperbilirubinemia after AAD surgery related to the severity of the AAD and the severity of injury during AAD operation. Additionally, perioperative hyperbilirubinemia has been proved to be associated with postoperative AKI in patients undergoing cardiac surgeries as well [10]. In animal model, hyperbilirubinemia was proved to have pro-apoptotic effects and aggravate renal ischemia-reperfusion injury [28]. Additionally, high concentration of bilirubin could lead to inflammatory response and cell apoptosis of the brain [29], which might be another potential mechanism of the high mortality of our present cohort. Despite improvement of AAD repair technology, the employment of deep hypothermic circulatory arrest and antegrade cerebral perfusion, the improvement of CBP strategies, and the availability of advanced organ support system, all of the included AAD patients had severe postoperation hyperbilirubinemia, and $81.9 \%$ of the included patients developed AKI during their hospital staying in the present study, which increased in-hospital mortality due to the patient severity.

\section{Risk factors of postoperative AKI and CRRT}

In our present cohort, older age, high preoperative $\mathrm{SCr}$ concentration, and pronged $\mathrm{CPB}$ time were identified as independent risk factors for AKI. Meanwhile, preoperative $\mathrm{SCr}$ concentration was also associated with the 
Table 4 Logistic regression analysis for in-hospital mortality

\begin{tabular}{|c|c|c|c|c|c|c|}
\hline \multirow[t]{2}{*}{ Characteristic } & \multicolumn{2}{|l|}{ Univariate logistic regression } & \multicolumn{2}{|c|}{$\begin{array}{l}\text { Multivariate logistic regression } \\
\text { (model 1) }\end{array}$} & \multicolumn{2}{|c|}{$\begin{array}{l}\text { Multivariate logistic regression } \\
\text { (model 2) }\end{array}$} \\
\hline & OR $(95 \% \mathrm{Cl})$ & $\boldsymbol{P}$ value & OR $(95 \% \mathrm{Cl})$ & $\boldsymbol{P}$ value & OR $(95 \% \mathrm{Cl})$ & $\boldsymbol{P}$ value \\
\hline Age (year) & $1.035(1.009-1.062)$ & 0.008 & $1.005(1.004-1.099)$ & 0.033 & $1.046(1.002-1.093)$ & 0.040 \\
\hline Male (yes/no) & $2.483(1.106-5.575)$ & 0.027 & & & & \\
\hline \multicolumn{7}{|l|}{ Preoperative } \\
\hline $\mathrm{SCr}$ & $1.009(1.002-1.016)$ & 0.008 & & & & \\
\hline APACHE II score & $1.178(1.082-1.282)$ & $<0.001$ & & & & \\
\hline \multicolumn{7}{|l|}{ Intraoperative } \\
\hline CPB time & $1.007(1.003-1.011)$ & 0.002 & & & & \\
\hline ACC time & $1.012(1.002-1.021)$ & 0.014 & & & & \\
\hline Deep hypothermic circulatory arrest time & $0.997(0.979-1.016)$ & 0.787 & & & & \\
\hline \multicolumn{7}{|l|}{ Postoperative } \\
\hline MAP & $0.948(0.926-0.971)$ & $<0.001$ & $0.955(0.922-0.990)$ & 0.012 & $0.963(0.930-0.977)$ & 0.031 \\
\hline Re-operation (yes/no) & $3.611(1.324-9.852)$ & 0.012 & & & & \\
\hline The total amount of blood transfusion & $1.046(1.032-1.060)$ & $<0.001$ & $1.018(1.003-1.033)$ & 0.019 & $1.020(1.005-1.034)$ & 0.007 \\
\hline Mechanical ventilation time & $1.533(1.341-1.798)$ & $<0.001$ & & & & \\
\hline AKI (yes/no) & $28.350(3.842-209.203)$ & 0.001 & & & & \\
\hline Stage of AKI & & $<0.001$ & & $<0.001$ & & $<0.001$ \\
\hline Stage 1 & $5.859(0.735-46.720)$ & 0.095 & $2.424(0.267-21.990)$ & 0.431 & $2.218(0.253-19.426)$ & 0.472 \\
\hline Stage 2 & $10.138(1.162-88.457)$ & 0.036 & $4.560(0.478-43.545)$ & 0.187 & $3.698(0.385-35.548)$ & 0.257 \\
\hline Stage 3 & 165.053 (21.354-1275.729) & $<0.001$ & $46.134(5.436-391.525)$ & $<0.001$ & $46.318(5.666-378.663)$ & $<0.001$ \\
\hline Use of CRRT (yes/no) & $23.756(10.359-54.481)$ & 0.001 & & & & \\
\hline Use of PE/BA (yes/no) & $11.527(2.432-54.631)$ & 0.002 & & & & \\
\hline Use of ECMO (yes/no) & $14.842(1.757-125.357)$ & 0.013 & $20.795(1.620-266.917)$ & 0.02 & $10.130(0.900-113.958)$ & 0.061 \\
\hline Peak TB concentration & $1.009(1.005-1.012)$ & $<0.001$ & $1.017(1.002-1.032)$ & 0.023 & & \\
\hline Peak TB $\geq 121$ mol/l, (yes/no) & $3.899(2.220-6.847)$ & $<0.001$ & & & $2.681(1.119-6.425)$ & 0.027 \\
\hline Time to peak TB concentration & $1.441(1.277-1.626)$ & $<0.001$ & & & & \\
\hline ICU stay time & $1.268(1.172-1.371)$ & $<0.001$ & & & & \\
\hline
\end{tabular}

Model 1 was established by analysis of peak TB concentration; Model 2 was established by subgroup analysis of peak bilirubin concentration greater or less than $121.2 \mu \mathrm{mol} / \mathrm{l}$

ACC Aortic cross clamp, AKI Acute kidney injury, APACHEIl Acute physiology and chronic health evaluation II, BA Bilirubin adsorption, CPB Cardiopulmonary bypass, CRRT Continuous renal replacement therapy, ECMO Extracorporeal membrane oxygenation, ICU Intensive care unit, MAP Mean arterial pressure, $P E$ Plasma exchange, SCr Serum creatinine, TB Total bilirubin

requirement of CRRT after AAD surgery. A recent meta-analysis of patients underwent AAD surgery [17] showed that older age was identified as an independent risk factor of AKI as well. Older age-mediated adverse renal structural and functional changes might contribute to the high development of postoperative AKI after AAD surgery in older patients. The aforementioned meta-analysis showed that preoperative $\mathrm{SCr}$ concentration did not correlate with postoperative AKI with significant heterogeneity $\left(\mathrm{I}^{2}=72.8 \%\right)$. In our opinion, preoperation elevated $\mathrm{SCr}$ concentration might indicate structural kidney damage or hemodynamic derangements in AAD patients, which further aggravated the development of post-operation $\mathrm{AKI}$ and the requirement of CRRT. Longer CPB time can lead to more hemolysis, and a longer time on the circuit can lead to changes in perfusion to the viscera and to more inflammatory action. A CPB itself might also induce hypoperfusion of abdominal organs, hypoxia or an inflammatory reaction, which causes liver and kidney damage. Therefore, surgeons most likely could reduce the AKI risk of AAD patients by the improvement of their operation strategies and the reduction of $\mathrm{CPB}$ time.

\section{Risk factors of in-hospital and long-term mortality}

In previous studies, older age had been identified as an independent risk factor of mortality for patients with hyperbilirubinemia after cardiac surgery [30]. In our present 


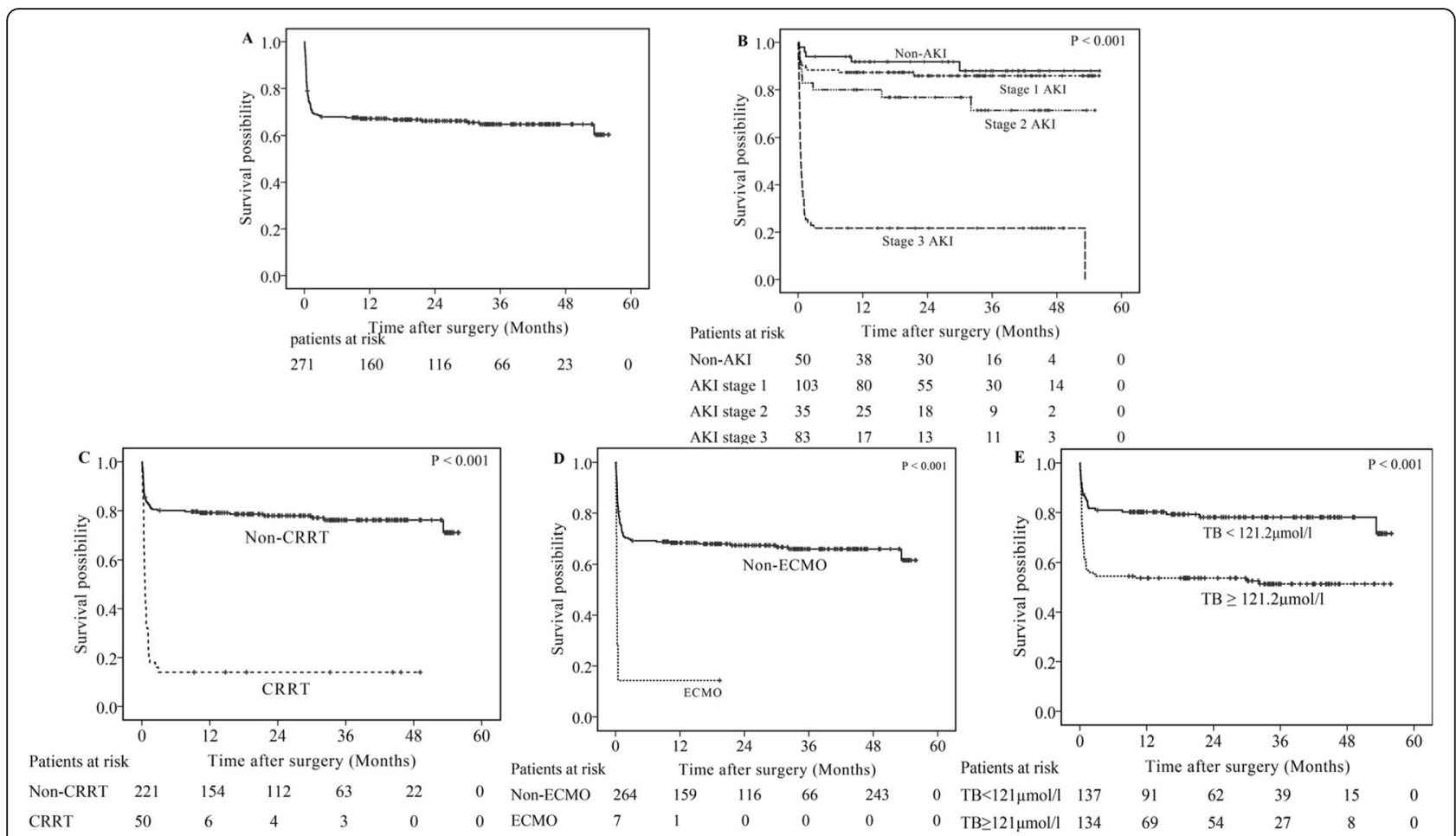

Fig. 3 Long-term survival results of (a) all patients, $\mathbf{b}$ patients without AKI and those with stage 1, 2, or 3 AKI, c patients without the use of CRRT and those with CRRT, $\mathbf{d}$ patients without the use of ECMO and those with ECMO, e patients with post-operation peak TB $\geq 121.2 \mu \mathrm{mol} / \mathrm{I}$ and those with post-operation peak TB $<121.2 \mu \mathrm{mol} / \mathrm{l}$

study, older age was established a risk factor for inhospital mortality for patients with hyperbilirubinemia after AAD surgery as well. Aging indicated diminished functional capacity of the liver and added to the cumulative burden in the case of developed severe hyperbilirubinemia. Additionally, different from the a recent study outlining the increased risk of mortality for patients with hyperbilirubinemia after cardiac surgery associated with time to peak bilirubin [14], our study indicated that peak TB concentration was an independent driver of inhospital mortality for patients with severe hyperbilirubinemia after AAD surgery. And, we found out that the optimal cut-off value of peak TB on predicting in-hospital mortality was $121.2 \mu \mathrm{mol} / \mathrm{l}$. This difference might be attributed to the existence of severe hyperbilirubinemia after AAD surgery and the limitation of small sample size. The high concentration of bilirubin leads to inflammatory response or cell apoptosis in the brain [29]. Cui et al. [31] showed that bilirubin induced lung edema and injury by inducing the apoptosis of alveolar epithelial cells. From the above, severe hyperbilirubinemia induces oxidative stress and apoptosis in many organs, which is associated with poor outcomes in patients with AAD surgery.

In a study for patients with jaundice after open heart surgery, Chu et al. [32] reported patients with more severe hyperbilirubinemia or delayed serum peak TB concentration might be significantly associated with more transfused blood and hypotension. Increased amount of blood transfusions contributed to hemolysis, and hypotension would reduce hepatic perfusion [33], which both caused an increased bilirubin load. This might be one of the potential mechanisms that the number of transfused blood units and lower MAP increased mortality in our present study. Previous studies suggested that mechanisms underlying the development of post-operation late peak TB concentration differed from those of the early peak bilirubin concentration. The immediate development of post-operation peak TB concentration and rapid decline thereafter reflected the transient damaging effects by $\mathrm{CPB}$ surgery, whereas late development of post-operation peak TB concentration was a consequence of hepatic dysfunction caused by persistent cardiac failure or sepsis [5, 7]. In the present study, multiple organ failure, cardiac failure, and sepsis were observed among hospitalized deaths as well. Therefore, attention should be paid to the monitoring of heart failure and optimizing hemodynamics after AAD surgery to prevent further deterioration. Furthermore, identifying and implementing effective risk reduction strategies is needed. Molecular adsorbent recirculation system, 
Table 5 COX regression analysis for long-term mortality

\begin{tabular}{|c|c|c|c|c|}
\hline \multirow[t]{2}{*}{ Characteristic } & \multicolumn{2}{|c|}{ Univariate COX regression } & \multicolumn{2}{|c|}{ Multivariate COX regression } \\
\hline & OR $(95 \% \mathrm{Cl})$ & $\boldsymbol{P}$ value & $\mathrm{OR}(95 \% \mathrm{Cl})$ & $\boldsymbol{P}$ value \\
\hline Age & $1.023(1.003-1.043)$ & 0.026 & & \\
\hline \multicolumn{5}{|l|}{ Preoperative } \\
\hline $\mathrm{SCr}$ & $1.006(1.002-1.010)$ & $<0.001$ & & \\
\hline APACHE II score & $1.122(1.060-1.188)$ & $<0.001$ & & \\
\hline MELD score & $1.052(1.003-1.105)$ & 0.039 & & \\
\hline \multicolumn{5}{|l|}{ Intraoperative } \\
\hline Operation duration & $1.248(1.098-1.414)$ & 0.001 & & \\
\hline CPB time & $1.005(1.002-1.008)$ & 0.001 & & \\
\hline \multicolumn{5}{|l|}{ Postoperative } \\
\hline MAP & $0.971(0.957-0.985)$ & $<0.001$ & $0.979(0.962-0.995)$ & 0.012 \\
\hline The total amount of blood transfusion & $1.009(1.007-1.011)$ & $<0.001$ & & \\
\hline Mechanical ventilation time & $1.035(1.020-1.051)$ & $<0.001$ & & \\
\hline AKI (yes/no) & $6.25(2.295-17.024)$ & $<0.001$ & & \\
\hline Stage of AKI & & $<0.001$ & & $<0.001$ \\
\hline Stage 1 & $1.404(0.506-3.901)$ & 0.515 & $1.037(0.365-2.946)$ & 0.946 \\
\hline Stage 2 & $2.772(0.929-8.271)$ & 0.068 & $2.236(0.774-6.990)$ & 0.133 \\
\hline Stage 3 & $15.071(6.043-37.587)$ & $<0.001$ & $12.604(5.002-31.762)$ & $<0.001$ \\
\hline Use of CRRT (yes/no) & 6.368 (4.174-9.709) & $<0.001$ & & \\
\hline Use of PE/BA (yes/no) & $3.184(1.596-6.351)$ & 0.001 & & \\
\hline Use of ECMO (yes/no) & $6.108(2.638-14.139)$ & $<0.001$ & $12.167(4.588-32.264)$ & $<0.001$ \\
\hline Onset of hyperbilirubinemia & $1.217(1.044-1.418)$ & 0.012 & & \\
\hline Peak TB concentration & $1.004(1.003-1.006)$ & $<0.001$ & & \\
\hline 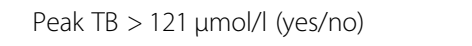 & $2.595(1.679-4.001)$ & $<0.001$ & & \\
\hline 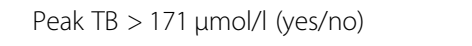 & $2.292(1.488-3.530)$ & $<0.001$ & & \\
\hline Time to peak TB concentration & $1.156(1.107-1.208)$ & $<0.001$ & & \\
\hline ICU stay time & $1.037(1.022-1.053)$ & $<0.001$ & & \\
\hline
\end{tabular}

ACC Aortic cross clamp, AKI Acute kidney injury, APACHEIl Acute physiology and chronic health evaluation II, BA Bilirubin adsorption, CPB Cardiopulmonary bypass, $C R R T$ Continuous renal replacement therapy, ECMO Extracorporeal membrane oxygenation, ICU Intensive care unit, MAP Mean arterial pressure, MELD Model for end-stage liver disease, PE Plasma exchange, SCr Serum creatinine, TB Total bilirubin

prometheus therapy, fractionated plasma separation and adsorption have shown promise in reducing bilirubin concentration [30, 34], but the ideal timing of blood purification initiation after cardiac surgery remains uncertain and further study in this area is needed.

AKI had been incorporated into a risk tool to predict early mortality for patients underwent AAD surgery [17]. Our results added to these findings and demonstrated stage 3 AKI markedly increased both in-hospital and longterm mortality. We found patients who had heart failure after cardiac surgery developed hyperbilirubinemia and AKI. Heart failure could cause reduced systemic blood flow, which leaded to inappropriate oxygen delivery and energy deficit. These caused kidney and liver damage, Additionally, severe hyperbilirubinemia aggravated renal ischemia-reperfusion injury and increased the incidence of severe AKI [28]. Additionally, we found most patients died of multiple organ failure or heart failure, which might be one of potential mechanism that AKI and severe hyperbilirubinemia were associated with high mortality. Additionally, our study also showed in-hospital and long-term mortality was independently predicted by the use of ECMO. Hemolysis is a common complication in ECMO support [35]. Pump head or oxygenator thrombosis and excessive pump speed (typically greater than $3000 \mathrm{rpm}$ ) which may destroy blood red cells [36], which in turn is important factor in the development of hyperbilirubinemia. Therefore, more careful postoperative management is needed to improve prognosis.

\section{Study limitation}

Our present study was a retrospective clinical research from a single institution and had some limitations. First, $\mathrm{SCr}$ concentration on admission was regard as 
preoperative renal function. However, some patients might already have AKI on admission. As a result, the number of patients with AKI may be underestimated. Second, the number of major adverse events including the use of ECMO, plasma exchange and bilirubin adsorption was small, which will be likely to reduce the statistical power for risk factor analysis. Finally, the renal prognosis was not regular followed up after the hospital discharge, which is important for the evaluation of the renal outcome. Therefore, further prospective multicenter studies with larger samples are needed to obtain stronger evidences.

\section{Conclusion}

Severe post-operation hyperbilirubinemia is a common clinical presentation in AAD surgery patients. Severe post-operation hyperbilirubinemia AAD patients with older age, lower MAP, increased blood transfusion, stage 3 AKI, the use of ECMO, and the increased peak TB had higher risk of in-hospital mortality. These patients most likely need more intensive monitoring.

\section{Supplementary information}

Supplementary information accompanies this paper at https://doi.org/10. 1186/s13019-020-01243-7.

Additional file 1: Figure S1. Receiver operator curve (ROC) of peak TB concentration predicting in-hospital mortality (area under the curve: 0.68, 95\% Cl: 0.614-0.758)

\section{Abbreviations}

AAD: Stanford type A aortic dissection; AKI: Acute kidney injury; ACC: Aortic cross clamp; APACHEll: Acute physiology and chronic health evaluation II; BA: Bilirubin adsorption; CPB: Cardiopulmonary bypass; CRRT: Continuous renal replacement therapy; ECMO: Extracorporeal membrane oxygenation; IABP: Intra-aortic balloon pump; ICU: Intensive care unit;" MAP: Mean arterial pressure; MELD: Model for end-stage liver disease; PE: Plasma exchange: SCr: Serum creatinine; SOFA : Sequential organ failure assessment; TB: Total bilirubin

\section{Acknowledgments}

Not applicable.

\section{Authors' contributions}

Chen, Bai, Zhao, and Sun analyzed and interpreted the data. Li, Yu, Zhang, $\mathrm{Ma}$ and Chen performed the statistical analyses. All authors contributed to the study design and interpretation of the study results. All authors read and approved the final manuscript.

\section{Funding}

This work was supported by the National Natural Science Foundation of China (81700584) and Discipline Promotion Project of Xijing Hospital (XJZT18ML16)

\section{Availability of data and materials}

The datasets used or analyzed during the current study are available from the corresponding author on reasonable request.

\section{Ethics approval and consent to participate}

The local Institutional Review Board of the hospital approved this retrospective study and waived the requirement of informed consent for the use of patients' medical data, and all experimental methods were performed in accordance with the relevant guidelines and regulations.
Consent for publication

Not applicable.

\section{Competing interests}

The authors have declared that no interest.

\section{Author details}

${ }^{1}$ The Nephrology Department of Xijing Hospital, the Fourth Military Medical University, No. 127 Changle West Road, Xi'an 710032, Shaanxi, China. ${ }^{2}$ State Key Laboratory of Kidney Disease, Department of Nephrology, Chinese People's Liberation Army General Hospital and Military Medical Postgraduate College, 28th Fuxing Road, Beijing 100853, China.

Received: 20 May 2020 Accepted: 20 July 2020

Published online: 28 July 2020

References

1. Nienaber CA, Clough RE. Management of acute aortic dissection. Lancet. 2015:385:800-11.

2. Nienaber CA, Clough RE, Sakalihasan N, Suzuki T, Gibbs R, Mussa F, et al. Aortic dissection. Nat Rev Dis Primers. 2016;2:16053.

3. Evangelista A, Isselbacher EM, Bossone E, Gleason TG, Eusanio MD, Sechtem $U$, et al. Insights from the international registry of acute aortic dissection: a 20-year experience of collaborative clinical research. Circulation. 2018;137: $1846-60$.

4. $\quad$ Ling Z, Wenqing $G$, Lei S, Zheng M, Liwen L, Xiaodong Z. Perioperative survival rate and relevant risk factors in patients with aortic dissection. Chin J Med Ultrasound(Electronic Edition). 2018;15:935-41.

5. Wang MJ, Chao A, Huang CH, Tsai CH, Lin FY, Wang SS, et al. Hyperbilirubinemia after cardiac operation. Incidence, risk factors, and clinical significance. J Thorac Cardiovasc Surg. 1994;108:429-36.

6. Nishi H, Sakaguchi T, Miyagawa S, Yoshikawa Y, Fukushima S, Saito S, et al. Frequency, risk factors and prognosis of postoperative hyperbilirubinemia after heart valve surgery. Cardiology (Switzerland). 2012;122:12-9.

7. Hsu RB, Lin FY, Chen RJ, Chou NK, Ko WJ, Chi NH, et al. Incidence, risk factors, and prognosis of postoperative hyperbilirubinemia after heart transplantation. Eur J Cardiothorac Surg. 2007;32:917-22.

8. An Y, Xiao YB, Zhong QJ. Hyperbilirubinemia after extracorporeal circulation surgery: a recent and prospective study. World J Gastroenterol. 2006;12: 6722-6

9. Yang L, Li J, Wang G, Zhou H, Fang Z, Shi S, et al. Postoperative liver dysfunction after total arch replacement combined with frozen elephant trunk implantation: incidence, risk factors and outcomes. Interact Cardiovasc Thorac Surg. 2019;29:930-6.

10. Kraev Al, Torosoff MT, Fabian T, Clement CM, Perez-Tamayo RA Postoperative hyperbilirubinemia is an independent predictor of longterm outcomes after cardiopulmonary bypass. J Am Coll Surg. 2008:206:645-53.

11. Collins JD, Bassendine MF, Ferner R, Blesovsky A, Murray A, Pearson DT, et al. Incidence and prognostic importance of jaundice after cardiopulmonary bypass surgery. Lancet (London, England). 1983;1:1119-23.

12. Sharma P, Ananthanarayanan C, Vaidhya N, Malhotra A, Shah K, Sharma R. Hyperbilirubinemia after cardiac surgery: An observational study. Asian Cardiovasc Thorac Ann. 2015;23:1039-43.

13. Lockey E, Mclntyre N, Ross DN, Brookes E, Sturridge MF. Early jaundice after open-heart surgery. Thorax. 1967;22:165-9.

14. Farag M, Veres G, Szabo G, Ruhparwar A, Karck M, Arif R. Hyperbilirubinaemia after cardiac surgery: the point of no return. ESC heart failure. 2019:6:694-700

15. Wang Y, Bellomo R. Cardiac surgery-associated acute kidney injury: risk factors, pathophysiology and treatment. Nat Rev Nephrol. 2017;13:697-711.

16. Michalopoulos A, Alivizatos P, Geroulanos S. Hepatic dysfunction following cardiac surgery: determinants and consequences. Hepato-gastroenterology. 1997:44:779-83.

17. Wang J, Yu W, Zhai G, Liu N, Sun L, Zhu J. Independent risk factors for postoperative $\mathrm{AKI}$ and the impact of the AKI on 30-day postoperative outcomes in patients with type a acute aortic dissection: an updated metaanalysis and meta-regression. J Thoracic Dis. 2018;10:2590-8.

18. Zhao H, Pan X, Gong Z, Zheng J, Liu Y, Zhu J, et al. Risk factors for acute kidney injury in overweight patients with acute type a aortic dissection: a retrospective study. J Thoracic Dis. 2015;7:1385-90. 
19. Zhou H, Wang G, Yang L, Shi S, Li J, Wang M, et al. Acute kidney injury after Total arch replacement combined with frozen elephant trunk implantation: incidence, risk factors, and outcome. J Cardiothorac Vasc Anesth. 2018;32: 2210-7.

20. Qiu Z, Chen L, Cao H, Zhang G, Xu F, Chen Q. Analysis of risk factors for acute kidney injury after ascending aortic replacement combined with open placement of triple-branched stent graft in type a aortic dissection: a new technique versus the traditional method in a single Chinese center. Med Sci Monitor. 2015;21:674-80.

21. Sasabuchi Y, Kimura N, Shiotsuka J, Komuro T, Mouri H, Ohnuma T, et al. Long-term survival in patients with acute kidney injury after acute type a aortic dissection repair. Ann Thorac Surg. 2016;102:2003-9.

22. Luo HY, Hu K, Liu ZY, Cheng Y, Zhao Y, Pan S, et al. Analysis of the risk factors of postoperative renal failure of type $\mathrm{A}$ aortic dissection. Zhonghua wai ke za zhi [Chinese journal of surgery]. 2008:46:1070-2.

23. Roh GU, Lee JW, Nam SB, Lee J, Choi JR, Shim YH. Incidence and risk factors of acute kidney injury after thoracic aortic surgery for acute dissection. Ann Thorac Surg. 2012;94:766-71.

24. Xu S, Liu J, Li L, Wu Z, Li J, Liu Y, et al. Cardiopulmonary bypass time is an independent risk factor for acute kidney injury in emergent thoracic aortic surgery: a retrospective cohort study. J Cardiothorac Surg. 2019;14:90.

25. Ko T, Higashitani M, Sato A, Uemura Y, Norimatsu T, Mahara K, et al. Impact of acute kidney injury on early to long-term outcomes in patients who underwent surgery for type a acute aortic dissection. Am J Cardiol. 2015 116:463-8.

26. Anil Z. Apaydin SB, Hakan Posacioglu, Fatih Islamoglu, Tanzer Calkavur, Tahir Yagdi, Mustafa Ozbaran and, Yuksel M. Perioperative Risk Factors for Mortality in Patients With Acute Type A Aortic Dissection. Ann Thorac Surg 2002;74:20342034-9.

27. Tsai HS, Tsai FC, Chen YC, Wu LS, Chen SW, Chu JJ, et al. Impact of acute kidney injury on one-year survival after surgery for aortic dissection. Ann Thorac Surg. 2012;94:1407-12.

28. Yuan L, Liao PP, Song HC, Zhou JH, Chu HC, Lyu L. Hyperbilirubinemia induces pro-apoptotic effects and aggravates renal ischemia reperfusion injury. Nephron. 2019;142:40-50.

29. Barateiro A, Domingues HS, Fernandes A, Relvas JB, Brites D. Rat cerebellar slice cultures exposed to bilirubin evidence reactive gliosis, excitotoxicity and impaired myelinogenesis that is prevented by AMPA and TNF-alpha inhibitors. Mol Neurobiol. 2014:49:424-39.

30. Komardina E, Yaroustovsky M, Abramyan M, Plyushch M. Prometheus therapy for the treatment of acute liver failure in patients after cardiac surgery. Kardiochir Torakochirurgia Pol. 2017;14:230-5.

31. Cui J, Zhao H, Yi B, Zeng J, Lu K, Ma D. Dexmedetomidine attenuates bilirubin-induced lung alveolar epithelial cell death in vitro and in vivo. Crit Care Med. 2015;43:e356-68.

32. Chu CM, Chang CH, Liaw YF, Hsieh MJ. Jaundice after open heart surgery: a prospective study. Thorax. 1984;39:52-6.

33. Mundth ED, Keller AR, Austen WG. Progressive hepatic and renal failure associated with low cardiac output following open-heart surgery. J Thorac Cardiovasc Surg. 1967;53:275-84.

34. Mitzner SR, Stange J, Klammt S, Risler T, Erley CM, Bader BD, et al. Improvement of hepatorenal syndrome with extracorporeal albumin dialysis MARS: results of a prospective, randomized, controlled clinical trial. Liver transpl. 2000;6:277-86.

35. Pan KC, McKenzie DP, Pellegrino V, Murphy D, Butt W. The meaning of a high plasma free haemoglobin: retrospective review of the prevalence of haemolysis and circuit thrombosis in an adult ECMO Centre over 5 years. Perfusion. 2016;31:223-31.

36. Toomasian JM, Bartlett RH. Hemolysis and ECMO pumps in the 21st century. Perfusion. 2011;26:5-6.

\section{Publisher's Note}

Springer Nature remains neutral with regard to jurisdictional claims in published maps and institutional affiliations.

Ready to submit your research? Choose BMC and benefit from:

- fast, convenient online submission

- thorough peer review by experienced researchers in your field

- rapid publication on acceptance

- support for research data, including large and complex data types

- gold Open Access which fosters wider collaboration and increased citations

- maximum visibility for your research: over $100 \mathrm{M}$ website views per year

At BMC, research is always in progress.

Learn more biomedcentral.com/submissions 